\title{
Cue-induced reinstatement of nicotine-seeking behavior in rats: effect of bupropion, persistence over repeated tests, and its dependence on training dose
}

\author{
Xiu Liu ${ }^{1}$, Anthony R. Caggiula ${ }^{1}$, Matthew I. Palmatier ${ }^{1}$, Eric C. Donny ${ }^{1}$, and Alan F. Sved ${ }^{2}$ \\ Xiu Liu: xiuliu@pitt.edu; Anthony R. Caggiula: ; Matthew I. Palmatier: ; Eric C. Donny: ; Alan F. Sved: \\ 1 Department of Psychology, University of Pittsburgh, Pittsburgh, PA 15260, USA \\ 2 Department of Neuroscience, University of Pittsburgh, Pittsburgh, PA 15260, USA
}

\begin{abstract}
Rationale-The motivational effects of nicotine-associated cues have been demonstrated in animal studies. However, it is unknown whether the effectiveness of nicotine cues in reinstating nicotineseeking varies with the extent of prior nicotine self-administration. In addition, the issue of whether bupropion (an FDA-approved smoking cessation medication) interferes with the conditioned incentive of nicotine cues remains to be addressed.
\end{abstract}

Objective-This study determined the relationship of cue-reinstated nicotine-seeking and the levels of prior self-administration and examined the effect of bupropion on cue-induced reinstatement of nicotine-seeking in comparison with that on self-administration.

Materials and methods-Male Sprague-Dawley rats were trained in daily 1-h sessions to intravenously self-administer nicotine at different doses $(0,0.015,0.03,0.06 \mathrm{mg} / \mathrm{kg} / \mathrm{infusion})$ and to associate an auditory/visual cue with each nicotine delivery. After extinction, three reinstatement tests at 15 day intervals were conducted with re-presentation of the cue without nicotine delivery. In separate groups of rats trained with $0.03 \mathrm{mg} / \mathrm{kg} /$ infusion nicotine, bupropion $(0,10,20,40 \mathrm{mg} / \mathrm{kg})$ was intraperitoneally administered to different groups before the reinstatement and in a withinsubject design before the self-administration tests.

Results-Cue-induced reinstatement of active lever responses was observed at all nicotine doses in the first reinstatement test, but at only the two highest doses during the second and third tests. The magnitude of reinstatement was positively correlated with level of prior responding for nicotine. Bupropion pretreatment decreased nicotine self-administration but enhanced cue-reinstated nicotineseeking.

Conclusions-These results demonstrate the positive correlation of cue-reinstated nicotineseeking with prior responding for nicotine self-administration and the persistence of the cue effect after taking higher doses of nicotine. The results of pharmacological tests suggest that although it is able to help achieve smoking cessation, bupropion may have little clinical benefit for the prevention of relapse associated with exposure to environmental smoking cues.

\section{Keywords}

Bupropion; Conditioned stimuli; Extinction; Nicotine; Nicotine-seeking behavior; Reinstatement; Self-administration 


\section{Introduction}

Due to increasing public awareness of the harmful effects of smoking and nicotine addiction, smokers seek treatment to quit. However, although there exists behavioral and pharmacological treatments designed to promote smoking cessation, the great majority of abstinent smokers relapse after a quit attempt (Balfour and Fagerstrom 1996; Shiffman et al. 1998; Fiore et al. 2000), and almost all smokers who relapsed after initial cessation pharmacotherapy return to smoking after subsequent quit attempts (Tonnesen et al. 1993; Gourlay et al. 1995; Gonzales et al. 2001). Therefore, the high rates of resumption of smoking after abstinence present a formidable challenge for the treatment of nicotine addiction.

One significant factor thought to be important in relapse of drug taking, including smoking, is exposure to environmental stimuli previously associated with drug intake (Stewart et al. 1984; Niaura et al. 1989; Childress et al. 1993; Drummond et al. 1995; O'Brien et al. 1998; Jones and Benowitz 2002). Smoking may involve more frequent pairings between environmental stimuli and nicotine intake (cigarette puffs, approximately 70,000 times each year) than any other drug-taking behavior. As such, cigarette smoking may be particularly effective in establishing the incentive properties of nicotine-associated environmental stimuli (cues), such as the smell and taste of cigarettes or contexts within which smoking occurs (Goldberg et al. 1981; Rose and Levin 1991; Balfour et al. 2000; Caggiula et al. 2001). Clinical studies have demonstrated that smoking cues produce physiological responses (Saumet and Dittmar 1985; Abrams et al. 1988; Niaura et al. 1989; Niaura et al. 1992), enhance the desire to smoke (Perkins et al. 1994; Droungas et al. 1995; Drobes and Tiffany 1997; McDermut and Haaga 1998; Lazev et al. 1999; Brody et al. 2002), and increase the rate, intensity, and time of smoking (Surawy et al. 1985; Mucha et al. 1998). Smoking denicotinized cigarettes (i.e., cue alone) produces an equal amount of smoke intake and similar or even higher levels of satisfaction compared to nicotine-containing cigarettes (i.e., cue plus nicotine) (Butschky et al. 1995; Gross et al. 1997; Rose et al. 2000). In recent animal studies, we (Liu et al. 2006; Liu et al. 2007) and others (LeSage et al. 2004; Cohen et al. 2005; Paterson et al. 2005) have found that reintroduction of nicotine-associated cues after extinction resulted in increased responding on the lever previously reinforced by nicotine delivery. Taken together, these data indicate that environmental stimuli repeatedly associated with the administration of nicotine acquire conditioned incentive value, which critically contributes to reinstatement of nicotine-seeking behavior in animals and smoking relapse in humans.

History of drug exposure, including degree of drug intake, has been identified as a factor in resumption of drug-seeking behavior. For instance, clinical literature shows that feelings of relief upon smoking are greater in heavy, when compared to light smokers (Parrott 1994, 2000; Adan et al. 2004) and suggests that conditioned responses to drug cues are positively correlated with the degree of alcohol dependence (Glautier and Drummond 1994; George et al. 2001). Recent animal studies using the $23 \mathrm{~h}$ /day self-administration paradigm showed that lever responding in the first extinction session was positively correlated with nicotine infusions earned during the first 2-h of self-administration (Harris et al. 2007) and seemed more resistant to extinction in animals on higher compared to lower doses of nicotine (O'Dell et al. 2007). Cue-induced reinstatement of 3,4 methylenedioxymethamphetamine (MDMA; an amphetamine derivative)-seeking in rats was positively correlated to the responses made during prior self-administration training (Ball et al. 2007). Rats with higher rates of cocaine selfadministration are more vulnerable to cue-induced reinstatement of cocaine-seeking (Sutton et al. 2000). Animal studies have also shown that levels of cocaine-priming-induced reinstatement are positively related to prior cocaine intake (Ahmed and Koob 1998; Deroche et al. 1999; Baker et al. 2001; Mantsch et al. 2004). However, it is unclear whether the magnitude of nicotine cue-induced reinstatement after extinction varies along with the animal's history of nicotine self-administration. Moreover, a previous report shows that nicotine cue 
effectively elicits recovery of nicotine-seeking responding after 25 days of abstinence from the drug in rats (Cohen et al. 2005), and increasing evidence has shown that conditioned reinstatement of cocaine-, heroin-, and ethanol-seeking responses is long-lasting and even increased with the passage of time (Ciccocioppo et al. 2001; Grimm et al. 2001; Bossert et al. 2005). Based on these facts, the present study (1) examined cue-induced reinstatement in rats that had been trained to self-administer different doses of nicotine, (2) determined whether the nicotine cue elicits drug-seeking responses over repeated tests after extinction and what the relationship is between this persistence and the amount of prior nicotine intake.

Bupropion is an FDA-approved medication for nicotine dependence. It has been proposed that this agent acts by blocking nicotinic acetylcholine receptors and inhibiting dopamine and norepinephrine reuptake (Nomikos et al. 1989; Fryer and Lukas 1999; Slemmer et al. 2000; $\mathrm{Li}$ et al. 2002). Bupropion has been reported to alleviate nicotine withdrawal symptoms in both humans and animals (Shiffman et al. 2000; Cryan et al. 2003; Malin et al. 2006), whereas it has had inconsistent effects on nicotine self-administration in animals (Bruijnzeel and Markou 2003; Rauhut et al. 2003; Shoaib et al. 2003). Although bupropion has been reported to decrease the level of craving for smoking (Durcan et al. 2002) and reduce cigarette cue-induced neural activation in anterior cingulate cortex (Brody et al. 2004), smoking abstinence rates at 1 year with bupropion treatment remain at only 22-33\% (Hurt et al. 1997; Jorenby et al. 1999; Hurt et al. 2003; Killen et al. 2006) and 35\% when combined with nicotine replacement therapy (Jorenby et al. 1999). It is unclear whether bupropion alters smoking relapse associated with exposure to environmental cues in abstinent smokers. Therefore, this study also examined the effect of bupropion on cue-induced reinstatement of nicotine-seeking behavior in rats in comparison with its effect on nicotine self-administration.

\section{Materials and methods}

\section{Subjects}

Male Sprague-Dawley rats (Charles River) weighing 225-250 g upon arrival were used. Animals were individually housed in a humidity- and temperature-controlled $\left(21-22^{\circ} \mathrm{C}\right)$ vivarium on a reversed light/dark cycle (lights on 1900 hours; off 0700 hours) with unlimited access to water. After 1 week habituation to the colony room, rats were placed on a foodrestriction ( $20 \mathrm{~g}$ chow/day) regimen throughout the experiments. Training and experimental sessions were conducted during the dark phase at the same time each day (0900-1500 hours). All experimental procedures were carried out in accordance with the National Institutes of Health Guide for the Care and Use of Laboratory Animals.

\section{Self-administration apparatus}

Operant training and reinstatement tests were conducted in operant chambers located inside sound-attenuating, ventilated cubicles (Med Associates, St. Albans, VT). The chambers were equipped with two retractable levers on one side panel and with a $28-\mathrm{V}$ white light above each lever as well as a red house light on the top of the chambers. Between the two levers was a food pellet trough. Intravenous nicotine injections were delivered by a drug delivery system with a syringe pump (Med Associates, model PHM100-10 rpm). Experimental events and data collection were controlled by an interfaced computer.

\section{Food training}

One day after the start of the food-restriction regimen, food training sessions began. Introduction of the levers and illumination of the red house light indicated the start of the sessions. The right lever was assigned as the active lever, each response at which was rewarded with delivery of a food pellet $(45 \mathrm{mg})$. The left lever was inactive. Sessions lasted 1-h with a maximum delivery of 75 food pellets on a fixed-ratio (FR) 1 schedule. After responding 
stabilized, the reinforcement schedule was increased to FR5. Food training was terminated after rats earned all 75 food pellets on the FR5 schedule. Successful food training was achieved within three to five sessions. During the food training sessions, the red house light remained on, and the compound auditory/visual stimulus that was used later as the cue was never presented.

\section{Surgery}

After food training, the rats were anesthetized with isoflurane and implanted with jugular catheters as described previously (Donny et al. 1999). Animals were allowed at least 7 days to recover from surgery. For the first 2 weeks after surgery, catheters were flushed twice a day with $0.1 \mathrm{ml}$ of sterile saline containing heparin $(20 \mathrm{U} / \mathrm{ml})$, ticarcillan $(14 \mathrm{mg} / \mathrm{ml})$, and streptokinase $(5 \mathrm{mg} / \mathrm{ml})$ to maintain catheter patency and prevent infection. Thereafter, the catheters were flushed with the heparinized saline before and after the experimental sessions throughout the studies.

\section{Nicotine self-administration/conditioning}

After recovery from surgery, rats were divided into four groups for different nicotine doses $(0$, $0.015,0.03,0.06 \mathrm{mg} / \mathrm{kg} / \mathrm{infusion}$, free base). In the training sessions, animals were placed in the operant conditioning chambers and connected to a drug delivery system. The daily $1-\mathrm{h}$ sessions were initiated by introduction of the two levers with illumination of the red house light. In the first five daily sessions, each response on the active lever resulted in a nicotine infusion ( $0.1 \mathrm{ml}$ volume over approximately $1 \mathrm{~s}$ ). During the following 3 days (sessions 6 to 8) the reinforcement schedule was increased to FR2 and then to an FR5 schedule for the remainder of the experiments. Each nicotine infusion was paired with presentation of an auditory/visual stimulus (cue), which consisted of a 5-s tone and illumination of the lever light for $20 \mathrm{~s}$. The latter indicated a 20 -s timeout period during which time responding was recorded, but not reinforced. Responses at the inactivate lever were recorded, but had no consequence. All rats received 30 daily self-administration/conditioning training (five sessions/week). Experimental events and data collection were controlled by an interfaced computer and software (Med Associates, MED-PC 2.0).

\section{Extinction}

After completion of the self-administration/conditioning sessions, the nicotine-reinforced responses were extinguished by withholding nicotine and its associated cue. Specifically, the daily 1-h extinction sessions began with illumination of the red chamber light which remained on throughout the session. Responses on the active lever resulted in the delivery of saline rather than nicotine without presentation of the light/tone stimulus. The criterion for extinction was 3 consecutive days in which the number of responses/session was either less than $20 \%$ of the number of responses/session that occurred during the last 3 days of nicotine self-administration or less than 20 responses/session, whichever came first.

\section{Reinstatement tests}

To determine whether the effectiveness of the nicotine cue in inducing reinstatement is longlasting and persistent over repeated tests, rats received three reinstatement tests. The first reinstatement test was conducted 1 day after completion of extinction (ten daily sessions). The second and third tests followed at 15 day intervals. As such, the three reinstatement tests were performed on days 11,26, and 41 after completion of self-administration/conditioning training. Each interval included 13 days during which animals remained in their home cage without experimental sessions followed by two daily re-extinction (same as extinction describer above) sessions to minimize the potential confounding effects of spontaneous recovery on subsequent reinstatement tests. All the reinstatement tests were conducted under conditions identical to 
those during self-administration/conditioning except that saline substituted for nicotine, i.e., active lever responses resulted in presentation of the cue without nicotine availability. The test sessions, including those described below, were not conducted on Mondays to eliminate possible rebound of responding after weekend off.

\section{Effect of bupropion on cue-induced reinstatement}

Animals used for this experiment received food training, surgery, nicotine self-administration/ conditioning, extinction, and reinstatement test procedures as described above with the following exceptions: (1) these rats were trained with only one nicotine dose of $0.03 \mathrm{mg} / \mathrm{kg} /$ infusion; (2) there was a single reinstatement test conducted 1 day after the extinction criterion was met. Thirty minutes before testing, bupropion $(0,10,20,40 \mathrm{mg} / \mathrm{kg})$ was administered intraperitoneally to different groups $(n=9-10)$.

\section{Effect of bupropion on nicotine self-administration}

Another set of rats $(n=14)$ was used for this experiment. To equalize nicotine selfadministration with that of the reinstatement tests, these animals also received the 30 daily selfadministration training sessions as described above. Then, the bupropion test sessions began. Bupropion $(0,10,20,40 \mathrm{mg} / \mathrm{kg})$ was intraperitoneally administered 30 min before test in a within-subject design. Every rat received each dose once by using a Latin Square design. Test sessions were performed every other day with a nondrug pretreatment session in between to eliminate possible carry-over effect of the drug.

\section{Data analyses}

Data were presented as the mean $( \pm \mathrm{SEM})$ number of lever responses. Two-way repeated measure analysis of variance (ANOVA) and one-way ANOVA were used to analyze the data wherever appropriate. Differences among individual means were verified by subsequent Fisher's protected least significant difference (PLSD) post hoc tests or paired $t$ tests.

\section{Results}

\section{Nicotine self-administration/conditioning and extinction}

By the end of the 30 daily 1-h self-administration training, rats developed stable operant responding for i.v. nicotine infusions. As shown in Table 1, animals in three nicotine groups exhibited significantly higher levels of responding on the active lever compared to saline controls. One-way ANOVA yielded significant group differences on active lever responses averaged across the final three sessions of the FR5 schedule [ $F(3,33)=18.18, p<0.0001]$. Subsequent Fisher's PLSD post hoc tests verified that all three nicotine groups were significantly $(p<0.01)$ different from the saline group and that there was a significant $(p<0.05)$ difference between $0.015 \mathrm{vs} 0.03 \mathrm{mg} / \mathrm{kg} /$ infusion groups. Similar analysis on nicotine intake $(\mathrm{mg} / \mathrm{kg} / \mathrm{h})$ among the three nicotine groups showed significant group effect $[F(2,24)=24.72$, $p<0.0001]$ and Fisher's PLSD post hoc tests verified significant differences among all groups detailed in Table 1. However, there were no significant differences in inactive lever responding averaged across the final three sessions or body weight as measured immediately after completion of the final self-administration/conditioning session.

During the extinction phase, saline substitution for nicotine and omission of the cue extinguished active lever responding (Fig. 1). All rats reached the extinction criterion within ten daily sessions. An overall repeated measures ANOVA on active lever responses yielded significant main effects of group $[F(3,33)=7.10, p<0.001]$ and session $[F(9,297)=50.72$, $p<0.0001]$ and a significant group $\times$ session interaction $[F(27,297)=6.32, p<0.0001]$. Subsequent Fisher's PLSD post hoc tests confirmed that all three nicotine groups were 
significantly $(p<0.01)$ different from saline rats but not from each other $(p>0.05)$. Further analysis for the three nicotine groups verified a significant change across sessions $[F(9,216)$ $=52.94, p<0.0001]$, indicating extinction of nicotine-maintained responding. There was no difference in inactive lever responses among groups or across sessions.

\section{Reinstatement tests}

In the first reinstatement test conducted 1 day after extinction (11 days after completion of selfadministration/conditioning), response-contingent re-presentations of the cue elicited recovery of responding on the active lever in all three nicotine groups but not the saline group (Fig. 2). A repeated measures ANOVA with session [extinction (averaged across the last three sessions) and reinstatement] as the within factor and group as the between factor revealed significant main effects of group $[F(3,33)=5.35, p<0.01]$ and session $[F(1,33)=55.63, p<0.0001]$ and a significant group $\times$ session interaction $[F(3,33)=6.65, p<0.01]$. As detailed in Fig. 2, further analyses verified that the number of reinstatement responses in all three nicotine groups was significantly higher than corresponding extinction responses and the "reinstatement" responses of saline rats, whereas there was no significant difference $(p>0.05)$ among nicotine groups, indicating similar levels of the cue-induced response reinstatement in all nicotine-exposed rats. Similar analyses on inactive lever responses showed no significant differences.

Calculation of Pearson coefficient on the data pooled across the three nicotine doses showed a positive correlation of cue-induced reinstatement with the number of responses made during self-administration/conditioning training ( $r=0.49 ; p<0.01$, Fig. 3$)$.

During the second reinstatement test conducted 15 days after first test, i.e., 30 days after completion of self-administration/conditioning training, rats on 0.03 and $0.06 \mathrm{mg} / \mathrm{kg} / \mathrm{infusion}$ but not $0.015 \mathrm{mg} / \mathrm{kg} /$ infusion or saline showed significant recovery of re-extinguished responding on the active lever (Fig. 4). A repeated measure ANOVA showed significant main effects of group $[F(3,28)=3.38, p<0.05]$ and session $[F(1,28)=14.10, p<0.001]$ and a significant group $\times$ session interaction $[F(3,28)=4.49, p<0.05]$. Further analysis verified that the number of cue-reinstated responses in the 0.03 and $0.06 \mathrm{mg} / \mathrm{kg} /$ infusion, but not $0.015 \mathrm{mg} / \mathrm{kg} /$ infusion or saline groups, was significantly $(p<0.01)$ higher than corresponding re-extinction baseline. Similar results were obtained in the last reinstatement test which was conducted 30 days after the first test, corresponding to 40 days after the final self-administration/conditioning session (Fig. 4). There were significant main effects of group $[F(3,28)=3.69, p<0.05]$ and session $[F$ $(1,28)=35.43, p<0.0001]$ and a significant group $\times$ session interaction $[F(3,28)=7.54, \mathrm{p}<0.001]$. Subsequent analysis verified significant $(p<0.01)$ response reinstatement in the 0.03 and 0.06 but not the lowest $0.015 \mathrm{mg} / \mathrm{kg} /$ infusion groups. The magnitude of reinstatement pooled across the two higher doses in the second $(r=0.45 ; p<0.05)$ and third $(r=0.50 ; \mathrm{p}<0.05)$ tests were also positively correlated to lever responding of self-administration/conditioning training phase.

\section{Effect of bupropion on cue-induced reinstatement}

Animals for these reinstatement/bupropion experiments also readily developed stable nicotine $(0.03 \mathrm{mg} / \mathrm{kg} /$ infusion$)$ self-administration in the 30 daily self-administration/conditioning training sessions. As these rats were divided into four groups for the reinstatement/bupropion test in a counterbalanced manner, there were no differences among groups in active lever responses and nicotine intake during self-administration/conditioning and during extinction sessions (data not shown). A one-way ANOVA on the reinstatement responses yielded a marginally significant effect of group $[F(3,35)=2.81, p=0.054]$, and further Fisher's PLSD post hoc tests produced a significant $(p<0.05)$ increase in cue-induced reinstatement in the 10 $\mathrm{mg} / \mathrm{kg}$ bupropion group above saline controls (Fig. 5, top). Responses on the inactive lever remained low and indistinguishable among groups (data not shown). 


\section{Effect of bupropion on nicotine self-administration}

A one-way ANOVA on the active lever responding data showed a significant dose effect $[F$ $(3,52)=3.31, p<0.05])$, and subsequent Fisher's PLSD post hoc test verified significant decrease of responses after pretreatment of bupropion at highest dose $(40 \mathrm{mg} / \mathrm{kg}$ ) compared to saline control and the other two lower dose conditions ( $p<0.05$, Fig. 5, below). The inactive lever responses did not change across all the tests (data no shown).

\section{Discussion}

There were three main findings of the present experiments. First, the magnitude of cue-induced reinstatement of nicotine-seeking behavior was positively correlated with the number of operant responses made during nicotine self-administration/conditioning training. Second, the conditioned incentive value of the nicotine cue persisted over repeated tests in rats trained with higher but not lower doses of nicotine, suggesting that neuroadaptive changes due to higher levels of nicotine exposure may underlie this persistence. Last, bupropion unexpectedly increased the cue-induced reinstatement of nicotine-seeking behavior, whereas it decreased nicotine self-administration at its highest dose. These pharmacological data suggest that this agent, albeit helping decrease cigarette consumption, may have little clinical benefit for preventing smoking relapse specifically associated with exposure to smoking-related environmental stimuli.

One issue that needs to be discussed is whether the cue-induced reinstatement of lever-pressing responses represents conditioned nicotine-seeking behavior. In the present responsereinstatement paradigm, like in most cases using similar procedures (Shaham et al. 2003 for a review), both nicotine and its associated stimulus (cue) were omitted during extinction after self-administration/conditioning training and re-presented in the reinstatement test to determine the conditioned incentive of the cue without further nicotine availability. In light of the fact that recent animal studies have shown that some sensory stimuli have intrinsic reinforcing properties and thereby support moderate levels of operant responding such as leverpressing (Donny et al. 2003; Palmatier et al. 2006; Chaudhri et al. 2007), it is reasonable to speculate that the increase of responding during re-presentation of the cue might be attributable to the possible reinforcing value of the cue regardless of its association with nicotine; this might then be misinterpreted as response-reinstatement induced by the conditioned incentive of the stimuli. To address this issue, the present study included a control group that received procedures exactly the same as other experimental groups with the exception that saline, rather than nicotine, was available during self-administration/conditioning training. As the stimulus, albeit the same as in other groups, was never associated with nicotine delivery and subjective actions of nicotine, it did not acquire conditioned reinforcement value. Responding on the active lever in this control group remained low and constant across the self-administration/ conditioning, extinction, and reinstatement phases. This finding indicates that the specific stimulus used in the present procedure had very little, if any, intrinsic reinforcing value. Particularly convincing is the observation that removal of the stimulus during extinction in this saline control group did not impact the level of responding. Therefore, the recovery of extinguished responding of nicotine groups during the reinstatement tests resulted from the conditioned incentive value of the stimulus due to its prior repeated association with nicotine infusion and pharmacological actions. Indeed, Palmatier et al. (2007) recently, by using a procedure that employed criteria established by Mackintosh (1974) for demonstrating conditioned reinforcement, verified that self-administered nicotine endowed its associated stimulus with conditioned reinforcing value.

One purpose of this study was to determine whether the magnitude of cue-induced reinstatement of nicotine-seeking varies as a function of the level of operant nicotine selfadministration. There was no difference in the magnitude of cue-induced reinstatement as 
measured by rates of responding among the three nicotine dose groups. This finding is in line with a previous observation (Zhang et al. 2004) that cue-induced reinstatement of heroinseeking was not different in rats trained to self-administer heroin on a wide range of doses (0.025-0.1 mg/kg/infusion). Together, these observations may suggest that drugs, in contrast to natural rewards such as food and water, once above threshold for effectiveness, produce a similar interoceptive state, which endows cues with similar conditioned incentive values. This argument gains support from the evenly distributed reinstatement data across the three nicotine doses as shown in Fig. 3. Importantly, when pooled across doses, the magnitude of reinstatement was positively related to the number of active lever responses made during nicotine self-administration/conditioning training phase. This result is consistent with previous observations that cue-induced reinstatement of MDMA-seeking in rats was positively correlated to the responses made during prior self-administration training (Ball et al. 2007) and that rats with higher rates of self-administration showed elevated levels of cue-induced reinstatement of cocaine-seeking (Tran-Nguyen et al. 1998; Sutton et al. 2000). Although there has been little systemic examination on the relationship between the magnitude of cue-induced drug-seeking and the parameters of drug self-administration/conditioning, the present data, together with the others, suggest that cue-induced reinstatement of drug-seeking behavior may be attributable to the number of operant responses and correspondingly the number of times the cue was associated with drug delivery during self-administration/conditioning training as long as the drug dose reaches its threshold for producing pharmacological actions.

Another objective of the present study was to examine whether motivational effects of the nicotine cue persist beyond the first reinstatement test and if the duration varies as a function of the amount of nicotine exposure. The results showed that during the second and third tests which were conducted 15 and 30 days after the first test, i.e., 26 and 41 days after completion of nicotine self-administration/conditioning, response-contingent re-presentation of the cue still effectively elicited reinstatement of nicotine-seeking responses. Although it was reported that intervening days after extinction would give rise to spontaneous recovery of responding for cocaine (Di Ciano and Everitt 2002) and nicotine (Shaham et al. 1997), increased lever responding during the repeated reinstatement tests of the present study was not readily attributable to this phenomenon because responding was re-extinguished immediately before each of these tests, and reinstatement was obtained only at the two higher nicotine doses.

Therefore, reinstatement was elicited specifically by re-presentation of the nicotine-associated cue, indicating that the conditioned incentive value of the nicotine cue is long-lasting. The persistence of cue-induced reinstatement of nicotine-seeking behavior is consistent with a previous report (Cohen et al. 2005) showing that a similar compound auditory/visual cue associated with nicotine self-administration was found to reinstate nicotine-seeking responding after 25 daily extinction sessions. This finding also keeps in line with observations showing long-lasting motivational effect of cues previously associated with other drugs of abuse such as cocaine, heroin, alcohol (e.g., Ciccocioppo et al. 2001; Grimm et al. 2001; Weiss et al. 2001; Di Ciano and Everitt 2002). Of significance is the finding that in the repeated reinstatement tests, cue-induced reinstatement of nicotine-seeking was obtained only at the two highest doses of nicotine. The explanation for the difference between higher nicotine dose groups and the lower one may reside in neuroadaptive changes that accrue after chronic high level of nicotine exposure (Ochoa et al. 1990; Miyata and Yanagita 2001; Rahman et al. 2004). For example, it has been found that after 25 daily 1 -h nicotine $(0.03 \mathrm{mg} / \mathrm{kg} /$ infusion $)$ self-administration sessions, rats had decreased basal dopamine levels in the nucleus accumbens and a blunted dopamine increase in response to nicotine challenge (Rahman et al. 2004).

It is interesting to note the finding that animals on different nicotine doses emitted similar levels of responding in the first extinction session and responding decreased similarly across the following daily sessions. It has long been proposed that responding during extinction sessions 
may provide a measure of the incentive-motivational properties of the drug (Markou et al. 1993). Recent nicotine studies using an extended ( $23 \mathrm{~h} /$ day) access of self-administration paradigm showed that levels of extinction responding remained higher in rats receiving the highest dose $(0.06 \mathrm{mg} / \mathrm{kg} / \mathrm{infusion})$ of nicotine compared to rats trained with lower doses (O'Dell et al. 2007) and that although the first day extinction responding did not vary as a function of total nicotine infusions/intake, there was a positive correlation of extinction with nicotine infusions earned during the first $2 \mathrm{~h}$ of the extended access (Harris et al. 2007). Moreover, a cocaine study reported that drug-seeking responding in rats trained to selfadminister higher doses of cocaine were more resistant to extinction than in rats on a lower dose (Valles et al. 2006). Although many differences may result in the discrepancy between present finding and other aforementioned observations, similar profiles of extinction responding across different doses of nicotine in this study suggest that the limited 1-h selfadministration of nicotine compared to extended access procedures might not be sensitive enough to detect variations in extinction behavior in rats. However, similar to this study, a previous cocaine study showed that rats trained to self-administer different doses of cocaine with either long or short access to the drug emitted similar levels of responding during the first extinction session with short-access rats exhibiting the highest extinction responses (Mantsch et al. 2004). Taken together, these data suggest that systemic characterization of extinction behavior in the context of self-administration of nicotine and other drugs of abuse as well deserves more experimental attention.

In the pharmacological tests, pretreatment with bupropion, contrary to expectation, seemed to enhance rather than attenuate cue-induced reinstatement of nicotine-seeking. The failure of bupropion to affect responding on the inactive lever makes less likely an explanation based on nonspecific arousal and/or motor activation by this agent. Although the effect of bupropion, in a strictly statistical sense, did not reach significance $(p=0.054)$, a parsimonious conclusion may be argued that bupropion failed to attenuate cue-elicited reinstatement of nicotine-seeking after extinction. Together with the fact that high recidivism rates occur in abstinent smokers on bupropion treatment (Hurt et al. 1997; Jorenby et al. 1999; Hurt et al. 2003; Killen et al. 2006), the finding suggests that this agent may have little clinical benefit for the prevention of relapse associated with exposure to smoking cues. Of course, it should be noted that the testing condition of this study differed remarkably from clinical situations. For example, bupropion was given acutely and immediately before testing in this study, whereas in humans, its use began before quitting and continued across withdrawal period and other interventions. Regarding mechanisms of the actions of bupropion, previous research indicates that bupropion functions as an inhibitor of dopamine and norepinephrine transporters and thereby increases activity of these neurotransmitter systems (Nomikos et al. 1989; Li et al. 2002). Recently, bupropion was found to increase responding for a sensory reinforcer, and this effect was blocked by an $\alpha$-adrenergic antagonist (prazosin) but not by the nicotinic antagonist mecamylamine (Mays et al. 2007). Based on these data, it is proposed that bupropion increases the response-reinstating effect of the nicotine cue by facilitation of dopaminergic neurotransmission via decreasing dopamine reuptake. This argument gains support from studies showing that dopaminergic blockade effectively attenuates cue-induced reinstatement of drug-seeking behavior (e.g., Crombag et al. 2002; Liu and Weiss 2002), whereas dopaminergic activation potentiates cue effect (e.g., De Vries et al. 1999). Another speculation that could be raised is that bupropion might act as a discriminative stimulus in place of nicotine and thereby increase lever responding during the test sessions. However, a previous observation that nicotine, given before the cue presentation in a similar reinstatement paradigm, did not increase responding (LeSage et al. 2004) argues again this possibility. In contrast to the effect of bupropion on reinstatement, in the nicotine self-administration tests, bupropion decreased lever-pressing responses/nicotine intake, and this effect was observed only at its highest dose $(40 \mathrm{mg} / \mathrm{kg}$ ) with low dose having no effect. This finding is consistent with a previous observation under similar testing condition (Bruijnzeel and Markou 2003). Bupropion acts also 
as an antagonist of nicotinic acetylcholine receptors (Fryer and Lukas 1999; Slemmer et al. 2000). The decrease of nicotine self-administration by bupropion may result from the antagonist actions of bupropion on nicotinic receptors (Bruijnzeel and Markou 2003; Rauhut et al. 2003).

In summary, this study reports that the magnitude of cue-induced reinstatement of nicotineseeking behavior is positively correlated with the amount of lever responding made during self-administration/conditioning phase. The motivational effect of the nicotine cue is longlasting and persistent over repeated tests in rats trained with higher but not lower doses of nicotine. This finding suggests that the persistence in motivational effect of the nicotine cue may result from neuroadaptive changes due to high levels of nicotine exposure. The results obtained from the pharmacological tests suggest that although it is able to decrease cigarette consumption and thereby help achieve smoking cessation, bupropion may have little clinical benefit for the prevention of smoking relapse associated with exposure to environmental smoking cues, which reconciles with the high recidivism rates of smoking in abstinent smokers on bupropion treatment (Hurt et al. 1997; Jorenby et al. 1999; Hurt et al. 2003; Killen et al. 2006).

\section{Acknowledgments}

This work was supported by NIH grant DA 17288 (X Liu) and DA 10464 (AR Caggiula) from the National Institute on Drug Abuse. The authors would like to thank Sheri Booth, Maysa Gharib, Laure Craven, and Nicole Roehrig for their technical assistance.

\section{References}

Abrams DB, Monti PM, Carey KB, Pinto RP, Jacobus SI. Reactivity to smoking cues and relapse: two studies of discriminant validity. Behav Res Ther 1988;26:225-233. [PubMed: 3408457]

Adan A, Prat G, Sanchez-Turet M. Effects of nicotine dependence on diurnal variations of subjective activation and mood. Addiction 2004;99:1599-1607. [PubMed: 15585051]

Ahmed SH, Koob GF. Transition from moderate to excessive drug intake: change in hedonic set point. Science 1998;282:298-300. [PubMed: 9765157]

Baker DA, Tran-Nguyen TL, Fuchs RA, Neisewander JL. Influence of individual differences and chronic fluoxetine treatment on cocaine-seeking behavior in rats. Psychopharmacology (Berl) 2001;155:1826. [PubMed: 11374332]

Balfour DJ, Fagerstrom KO. Pharmacology of nicotine and its therapeutic use in smoking cessation and neurodegenerative disorders. Pharmacol Ther 1996;72:51-81. [PubMed: 8981571]

Balfour DJ, Wright AE, Benwell ME, Birrell CE. The putative role of extra-synaptic mesolimbic dopamine in the neurobiology of nicotine dependence. Behav Brain Res 2000;113:73-83. [PubMed: 10942034]

Ball KT, Walsh KM, Rebec GV. Reinstatement of MDMA (ecstasy) seeking by exposure to discrete drug-conditioned cues. Pharmacol Biochem Behav 2007;87:420-425. [PubMed: 17602729]

Bossert JM, Ghitza UE, Lu L, Epstein DH, Shaham Y. Neurobiology of relapse to heroin and cocaine seeking: an update and clinical implications. Eur J Pharmacol 2005;526:36-50. [PubMed: 16289451]

Brody AL, Mandelkern MA, London ED, Childress AR, Lee GS, Bota RG, Ho ML, Saxena S, Baxter LR Jr, Madsen D, Jarvik ME. Brain metabolic changes during cigarette craving. Arch Gen Psychiatry 2002;59:1162-1172. [PubMed: 12470133]

Brody AL, Mandelkern MA, Lee G, Smith E, Sadeghi M, Saxena S, Jarvik ME, London ED. Attenuation of cue-induced cigarette craving and anterior cingulate cortex activation in bupropion-treated smokers: a preliminary study. Psychiatry Res 2004;130:269-281. [PubMed: 15135160]

Bruijnzeel AW, Markou A. Characterization of the effects of bupropion on the reinforcing properties of nicotine and food in rats. Synapse 2003;50:20-28. [PubMed: 12872290] 
Butschky MF, Bailey D, Henningfield JE, Pickworth WB. Smoking without nicotine delivery decreases withdrawal in 12-hour abstinent smokers. Pharmacol Biochem Behav 1995;50:91-96. [PubMed: 7700960]

Caggiula AR, Donny EC, White AR, Chaudhri N, Booth S, Gharib MA, Hoffman A, Perkins KA, Sved AF. Cue dependency of nicotine self-administration and smoking. Pharmacol Biochem Behav 2001;70:515-530. [PubMed: 11796151]

Chaudhri N, Caggiula AR, Donny EC, Booth S, Gharib M, Craven L, Palmatier MI, Liu X, Sved AF. Self-administered and noncontingent nicotine enhance reinforced operant responding in rats: impact of nicotine dose and reinforcement schedule. Psychopharmacology (Berl) 2007;190:353-362. [PubMed: 16847680]

Childress AR, Hole AV, Ehrman RN, Robbins SJ, McLellan AT, O’Brien CP. Cue reactivity and cue reactivity interventions in drug dependence. NIDA Res Monogr 1993;137:73-95. [PubMed: 8289929]

Ciccocioppo R, Angeletti S, Weiss F. Long-lasting resistance to extinction of response reinstatement induced by ethanol-related stimuli: role of genetic ethanol preference. Alcohol Clin Exp Res 2001;25:1414-1419. [PubMed: 11696659]

Cohen C, Perrault G, Griebel G, Soubrie P. Nicotine-associated cues maintain nicotine-seeking behavior in rats several weeks after nicotine withdrawal: reversal by the cannabinoid (CB1) receptor antagonist, rimonabant (SR141716). Neuropsychopharmacology 2005;30:145-155. [PubMed: 15292905]

Crombag HS, Grimm JW, Shaham Y. Effect of dopamine receptor antagonists on renewal of cocaine seeking by reexposure to drug-associated contextual cues. Neuropsychopharmacology 2002;27:1006-1015. [PubMed: 12464457]

Cryan JF, Bruijnzeel AW, Skjei KL, Markou A. Bupropion enhances brain reward function and reverses the affective and somatic aspects of nicotine withdrawal in the rat. Psychopharmacology (Berl) 2003;168:347-358. [PubMed: 12698231]

De Vries TJ, Schoffelmeer AN, Binnekade R, Vanderschuren LJ. Dopaminergic mechanisms mediating the incentive to seek cocaine and heroin following long-term withdrawal of IV drug selfadministration. Psychopharmacology (Berl) 1999;143:254-260. [PubMed: 10353427]

Deroche V, Le Moal M, Piazza PV. Cocaine self-administration increases the incentive motivational properties of the drug in rats. Eur J Neurosci 1999;11:2731-2736. [PubMed: 10457169]

Di Ciano P, Everitt BJ. Reinstatement and spontaneous recovery of cocaine-seeking following extinction and different durations of withdrawal. Behav Pharmacol 2002;13:397-405. [PubMed: 12394416]

Donny EC, Caggiula AR, Mielke MM, Booth S, Gharib MA, Hoffman A, Maldovan V, Shupenko C, McCallum SE. Nicotine self-administration in rats on a progressive ratio schedule of reinforcement. Psychopharmacology (Berl) 1999;147:135-142. [PubMed: 10591880]

Donny EC, Chaudhri N, Caggiula AR, Evans-Martin FF, Booth S, Gharib MA, Clements LA, Sved AF. Operant responding for a visual reinforcer in rats is enhanced by noncontingent nicotine: implications for nicotine self-administration and reinforcement. Psychopharmacology (Berl) 2003;169:68-76. [PubMed: 12774186]

Drobes DJ, Tiffany ST. Induction of smoking urge through imaginal and in vivo procedures: physiological and self-report manifestations. J Abnorm Psychol 1997;106:15-25. [PubMed: 9103714]

Droungas A, Ehrman RN, Childress AR, O'Brien CP. Effect of smoking cues and cigarette availability on craving and smoking behavior. Addict Behav 1995;20:657-673. [PubMed: 8712062]

Drummond, DC.; Tiffany, ST.; Glautier, S.; Remington, B. Addictive behavior: cue exposure theory and practice. Wiley; New York: 1995.

Durcan MJ, Deener G, White J, Johnston JA, Gonzales D, Niaura R, Rigotti N, Sachs DP. The effect of bupropion sustained-release on cigarette craving after smoking cessation. Clin Ther 2002;24:540551. [PubMed: 12017399]

Fiore, MC.; Bailey, WC.; Cohen, SJ.; Dorfman, SF.; Goldstein, MG.; Giritz, ER.; Heyman, RB.; Jaen, CR.; Kottke, TE.; Lando, HE., et al. Clinical Practice Guideline, Public Health Service. US Department of Health and Human Services; Rockville, MD: 2000 Jun. Treating tobacco use and dependence. AHRQ Publication no. 00-0032 
Fryer JD, Lukas RJ. Noncompetitive functional inhibition at diverse, human nicotinic acetylcholine receptor subtypes by bupropion, phencyclidine, and ibogaine. J Pharmacol Exp Ther 1999;288:8892. [PubMed: 9862757]

George MS, Anton RF, Bloomer C, Teneback C, Drobes DJ, Lorberbaum JP, Nahas Z, Vincent DJ. Activation of prefrontal cortex and anterior thalamus in alcoholic subjects on exposure to alcoholspecific cues. Arch Gen Psychiatry 2001;58:345-352. [PubMed: 11296095]

Glautier S, Drummond DC. Alcohol dependence and cue reactivity. J Stud Alcohol 1994;55:224-229. [PubMed: 8189743]

Goldberg SR, Spealman RD, Goldberg DM. Persistent behavior at high rates maintained by intravenous self-administration of nicotine. Science 1981;214:573-575. [PubMed: 7291998]

Gonzales DH, Nides MA, Ferry LH, Kustra RP, Jamerson BD, Segall N, Herrero LA, Krishen A, Sweeney A, Buaron K, Metz A. Bupropion SR as an aid to smoking cessation in smokers treated previously with bupropion: a randomized placebo-controlled study. Clin Pharmacol Ther 2001;69:438-444. [PubMed: 11406741]

Gourlay SG, Forbes A, Marriner T, Pethica D, McNeil JJ. Double blind trial of repeated treatment with transdermal nicotine for relapsed smokers. BMJ 1995;311:363-366. [PubMed: 7640544]

Grimm JW, Hope BT, Wise RA, Shaham Y. Neuroadaptation. Incubation of cocaine craving after withdrawal. Nature 2001;412:141-142. [PubMed: 11449260]

Gross J, Lee J, Stitzer ML. Nicotine-containing versus denicotinized cigarettes: effects on craving and withdrawal. Pharmacol Biochem Behav 1997;57:159-165. [PubMed: 9164567]

Harris AC, Pentel PR, Lesage MG. Prevalence, magnitude, and correlates of an extinction burst in drugseeking behavior in rats trained to self-administer nicotine during unlimited access $(23 \mathrm{~h} /$ day $)$ sessions. Psychopharmacology (Berl) 2007;194:395-402. [PubMed: 17611741]

Hurt RD, Sachs DP, Glover ED, Offord KP, Johnston JA, Dale LC, Khayrallah MA, Schroeder DR, Glover PN, Sullivan CR, Croghan IT, Sullivan PM. A comparison of sustained-release bupropion and placebo for smoking cessation. N Engl J Med 1997;337:1195-1202. [PubMed: 9337378]

Hurt RD, Krook JE, Croghan IT, Loprinzi CL, Sloan JA, Novotny PJ, Kardinal CG, Knost JA, Tirona MT, Addo F, Morton RF, Michalak JC, Schaefer PL, Porter PA, Stella PJ. Nicotine patch therapy based on smoking rate followed by bupropion for prevention of relapse to smoking. J Clin Oncol 2003;21:914-920. [PubMed: 12610193]

Jones, RT.; Benowitz, NL. Therapeutics for nicotine addiction in neuropsychopharmacology. In: Davis, KL.; Charney, D.; Colyle, JT.; Nemeroff, C., editors. The fifth generation of progress. Lippincott, Williams \& Wilkins; Philadelphia: 2002. p. 1533-1543.

Jorenby DE, Leischow SJ, Nides MA, Rennard SI, Johnston JA, Hughes AR, Smith SS, Muramoto ML, Daughton DM, Doan K, Fiore MC, Baker TB. A controlled trial of sustained-release bupropion, a nicotine patch, or both for smoking cessation. N Engl J Med 1999;340:685-691. [PubMed: 10053177]

Killen JD, Fortmann SP, Murphy GM Jr, Hayward C, Arredondo C, Cromp D, Celio M, Abe L, Wang Y, Schatzberg AF. Extended treatment with bupropion SR for cigarette smoking cessation. J Consult Clin Psychol 2006;74:286-294. [PubMed: 16649873]

Lazev AB, Herzog TA, Brandon TH. Classical conditions of environmental cues to cigarette smoking. Exp Clin Psychopharmacol 1999;7:56-63. [PubMed: 10036610]

LeSage MG, Burroughs D, Dufek M, Keyler DE, Pentel PR. Reinstatement of nicotine self-administration in rats by presentation of nicotine-paired stimuli, but not nicotine priming. Pharmacol Biochem Behav 2004;79:507-513. [PubMed: 15582022]

Li SX, Perry KW, Wong DT. Influence of fluoxetine on the ability of bupropion to modulate extracellular dopamine and norepinephrine concentrations in three mesocorticolimbic areas of rats. Neuropharmacology 2002;42:181-190. [PubMed: 11804614]

Liu X, Weiss F. Reversal of ethanol-seeking behavior by D1 and D2 antagonists in an animal model of relapse: differences in antagonist potency in previously ethanol-dependent versus nondependent rats. J Pharmacol Exp Ther 2002;300:882-889. [PubMed: 11861794]

Liu X, Caggiula AR, Yee SK, Nobuta H, Poland RE, Pechnick RN. Reinstatement of nicotine-seeking behavior by drug-associated stimuli after extinction in rats. Psychopharmacology (Berl) 2006;184:417-425. [PubMed: 16163522] 
Liu X, Caggiula AR, Yee SK, Nobuta H, Sved AF, Pechnick RN, Poland RE. Mecamylamine attenuates cue-induced reinstatement of nicotine-seeking behavior in rats. Neuropsychopharmacology 2007;32:710-718. [PubMed: 16794568]

Mackintosh, NJ. The psychology of animal learning. Academic; New York: 1974.

Malin DH, Lake JR, Smith TD, Khambati HN, Meyers-Paal RL, Montellano AL, Jennings RE, Erwin DS, Presley SE, Perales BA. Bupropion attenuates nicotine abstinence syndrome in the rat. Psychopharmacology (Berl) 2006;184:494-503. [PubMed: 16163521]

Mantsch JR, Yuferov V, Mathieu-Kia AM, Ho A, Kreek MJ. Effects of extended access to high versus low cocaine doses on self-administration, cocaine-induced reinstatement and brain mRNA levels in rats. Psychopharmacology (Berl) 2004;175:26-36. [PubMed: 15042275]

Markou A, Weiss F, Gold LH, Caine BS, Schulteis G, Koob GF. Animal models of drug craving. Psychopharmacology 1993;112:163-182. [PubMed: 7871016]

Mays, KL.; Levin, ME.; Bak, KM.; Palmatier, MI.; Liu, X.; Caggiula, AR.; Donny, EC.; Craven, L.; Sved, AF. Nicotine and bupropion have similar effects on responding for reinforcing non-drug stimuli. Society for Research on Nicotine and Tobacco Annual Meeting; Austin, TX. 2007.

McDermut W, Haaga DA. Effect of stage of change on cue reactivity in continuing smokers. Exp Clin Psychopharmacol 1998;6:316-324. [PubMed: 9725115]

Miyata H, Yanagita T. Neurobiological mechanisms of nicotine craving. Alcohol 2001;24:87-93. [PubMed: 11522428]

Mucha RF, Pauli P, Angrilli A. Conditioned responses elicited by experimentally produced cues for smoking. Can J Physiol Pharmacol 1998;76:259-268. [PubMed: 9673789]

Niaura R, Abrams D, Demuth B, Pinto R, Monti P. Responses to smoking-related stimuli and early relapse to smoking. Addict Behav 1989;14:419-428. [PubMed: 2782124]

Niaura R, Abrams DB, Pedraza M, Monti PM, Rohsenow DJ. Smokers' reactions to interpersonal interaction and presentation of smoking cues. Addict Behav 1992;17:557-566. [PubMed: 1488936]

Nomikos GG, Damsma G, Wenkstern D, Fibiger HC. Acute effects of bupropion on extracellular dopamine concentrations in rat striatum and nucleus accumbens studied by in vivo microdialysis. Neuropsychopharmacology 1989;2:273-279. [PubMed: 2482026]

O'Brien CP, Childress AR, Ehrman R, Robbins SJ. Conditioning factors in drug abuse: can they explain compulsion? J Psychopharmacol 1998;12:15-22. [PubMed: 9584964]

O'Dell LE, Chen SA, Smith RT, Specio SE, Balster RL, Paterson NE, Markou A, Zorrilla EP, Koob GF. Extended access to nicotine self-administration leads to dependence: Circadian measures, withdrawal measures, and extinction behavior in rats. J Pharmacol Exp Ther 2007;320:180-193. [PubMed: 17050784]

Ochoa EL, Li L, McNamee MG. Desensitization of central cholinergic mechanisms and neuroadaptation to nicotine. Mol Neurobiol 1990;4:251-287. [PubMed: 2135395]

Palmatier MI, Liu X, Matteson GL, Donny EC, Caggiula AR, Sved AF. Conditioned reinforcement in rats established with self-administered nicotine and enhanced by noncontingent nicotine. Psychopharmacology (Berl). 200710.1007/s00213-007-0897-6

Parrott AC. Individual differences in stress and arousal during cigarette smoking. Psychopharmacology (Berl) 1994;115:389-396. [PubMed: 7871081]

Parrott AC. Cigarette smoking does cause stress. Am Psychol 2000;55:1159-1160. [PubMed: 11080843]

Paterson NE, Froestl W, Markou A. Repeated administration of the GABAB receptor agonist CGP44532 decreased nicotine self-administration, and acute administration decreased cue-induced reinstatement of nicotine-seeking in rats. Neuropsychopharmacology 2005;30:119-128. [PubMed: 15266350]

Perkins KA, Grobe JE, Fonte C, Goettler J, Caggiula AR, Reynolds WA, Stiller RL, Scierka A, Jacob RG. Chronic and acute tolerance to subjective, behavioral and cardiovascular effects of nicotine in humans. J Pharmacol Exp Ther 1994;270:628-638. [PubMed: 8071855]

Rahman S, Zhang J, Engleman EA, Corrigall WA. Neuro-adaptive changes in the mesoaccumbens dopamine system after chronic nicotine self-administration: a microdialysis study. Neuroscience 2004;129:415-424. [PubMed: 15501598]

Rauhut AS, Neugebauer N, Dwoskin LP, Bardo MT. Effect of bupropion on nicotine self-administration in rats. Psychopharmacology (Berl) 2003;169:1-9. [PubMed: 12811464] 
Rose JE, Levin ED. Inter-relationships between conditioned and primary reinforcement in the maintenance of cigarette smoking. Br J Addict 1991;86:605-609. [PubMed: 1859927]

Rose JE, Behm FM, Westman EC, Johnson M. Dissociating nicotine and nonnicotine components of cigarette smoking. Pharmacol Biochem Behav 2000;67:71-81. [PubMed: 11113486]

Saumet JL, Dittmar A. Heat loss and anticipatory finger vasoconstriction induced by a smoking of a single cigarette. Physiol Behav 1985;35:229-232. [PubMed: 4070388]

Shaham Y, Adamson LK, Grocki S, Corrigall WA. Reinstatement and spontaneous recovery of nicotine seeking in rats. Psychopharmacology (Berl) 1997;130:396-403. [PubMed: 9160857]

Shaham Y, Shalev U, Lu L, De Wit H, Stewart J. The reinstatement model of drug relapse: history, methodology and major findings. Psychopharmacology (Berl) 2003;168:3-20. [PubMed: 12402102]

Shiffman S, Mason KM, Henningfield JE. Tobacco dependence treatments: review and prospectus. Annu Rev Public Health 1998;19:335-358. [PubMed: 9611623]

Shiffman S, Johnston JA, Khayrallah M, Elash CA, Gwaltney CJ, Paty JA, Gnys M, Evoniuk G, DeVeaugh-Geiss J. The effect of bupropion on nicotine craving and withdrawal. Psychopharmacology (Berl) 2000;148:33-40. [PubMed: 10663415]

Shoaib M, Sidhpura N, Shafait S. Investigating the actions of bupropion on dependence-related effects of nicotine in rats. Psychopharmacology (Berl) 2003;165:405-412. [PubMed: 12451438]

Slemmer JE, Martin BR, Damaj MI. Bupropion is a nicotinic antagonist. J Pharmacol Exp Ther 2000;295:321-327. [PubMed: 10991997]

Stewart J, de Wit H, Eikelboom R. Role of unconditioned and conditioned drug effects in the selfadministration of opiates and stimulants. Psychol Rev 1984;91:251-268. [PubMed: 6571424]

Surawy C, Stepney R, Cox T. Does watching others smoke increase smoking? Br J Addict 1985;80:207210. [PubMed: 3860242]

Sutton MA, Karanian DA, Self DW. Factors that determine a propensity for cocaine-seeking behavior during abstinence in rats. Neuropsychopharmacology 2000;22:626-641. [PubMed: 10788762]

Tonnesen P, Norregaard J, Sawe U, Simonsen K. Recycling with nicotine patches in smoking cessation. Addiction 1993;88:533-539. [PubMed: 8485431]

Tran-Nguyen LT, Fuchs RA, Coffey GP, Baker DA, O’Dell LE, Neisewander JL. Time-dependent changes in cocaine-seeking behavior and extracellular dopamine levels in the amygdala during cocaine withdrawal. Neuropsychopharmacology 1998;19:48-59. [PubMed: 9608576]

Valles R, Rocha A, Nation JR. The effects of acquisition training schedule on extinction and reinstatement of cocaine self-administration in male rats. Exp Clin Psychopharmacol 2006;14:245-253. [PubMed: 16756428]

Weiss F, Martin-Fardon R, Ciccocioppo R, Kerr TM, Smith DL, Ben-Shahar O. Enduring resistance to extinction of cocaine-seeking behavior induced by drug-related cues. Neuropsychopharmacology 2001;25:361-372. [PubMed: 11522464]

Zhang F, Zhou W, Tang S, Lai M, Liu H, Yang G. Motivation of heroin-seeking elicited by drugassociated cues is related to total amount of heroin exposure during self-administration in rats. Pharmacol Biochem Behav 2004;79:291-298. [PubMed: 15501304] 


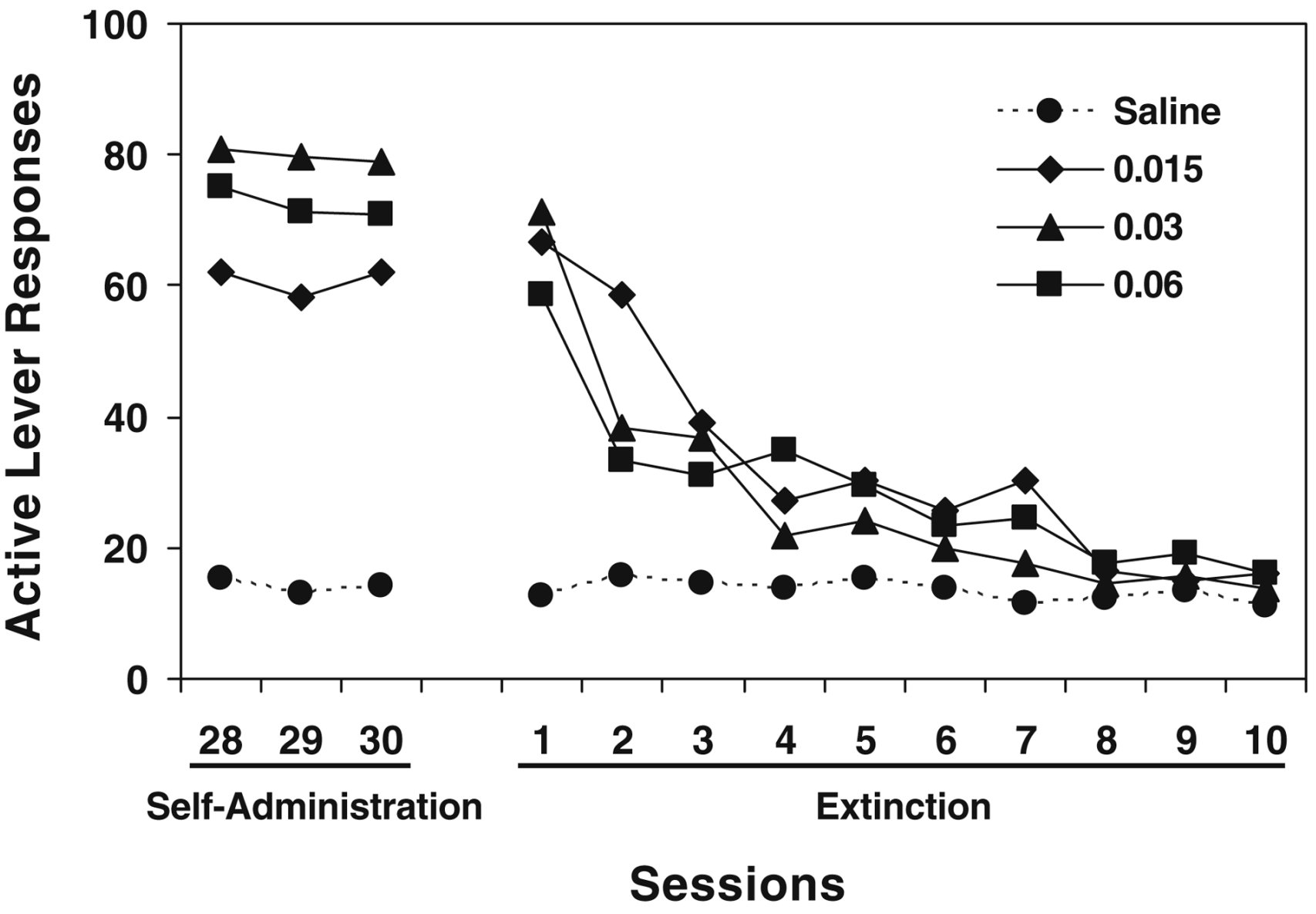

Fig. 1.

Responses made on the active lever in the last three sessions of nicotine self-administration/ conditioning and during subsequent extinction sessions. For the purpose of clarity, the standard error of mean was not shown. See text for statistical details 

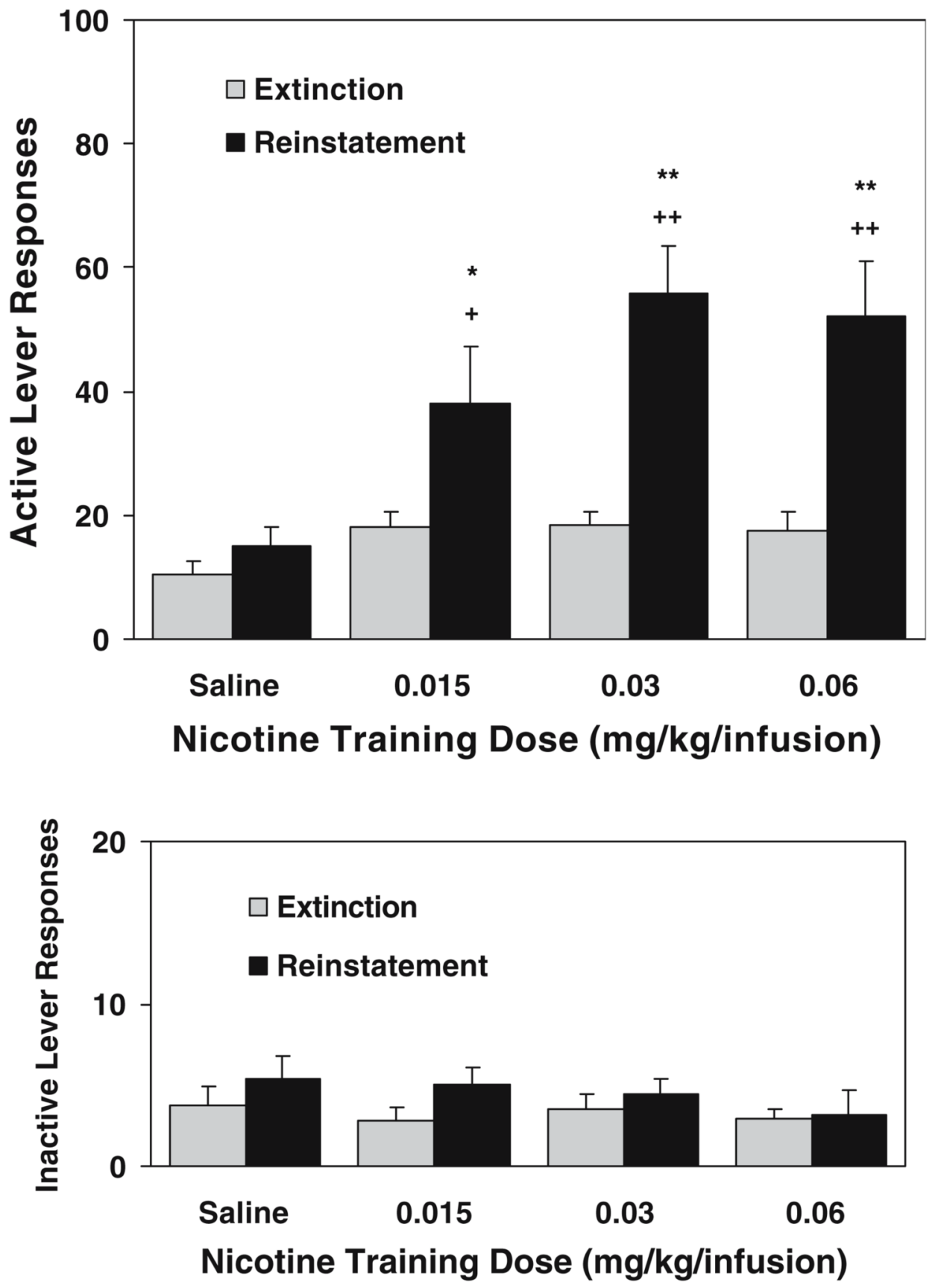

Fig. 2.

Lever responses in the reinstatement test sessions $(n=9-10)$. The test sessions were performed 1 day after completion of extinction that followed 30 daily 1-h self-administration/conditioning training. Responses on the active lever resulted in presentation of the nicotine cue without delivery of nicotine (saline substitution). The number of responses is presented as the mean \pm SEM. ${ }^{*} p<0.05,{ }^{* *} P<0.01$ different from corresponding extinction. ${ }^{+} p<0.05,{ }^{++} P<0.01$ different from saline group 


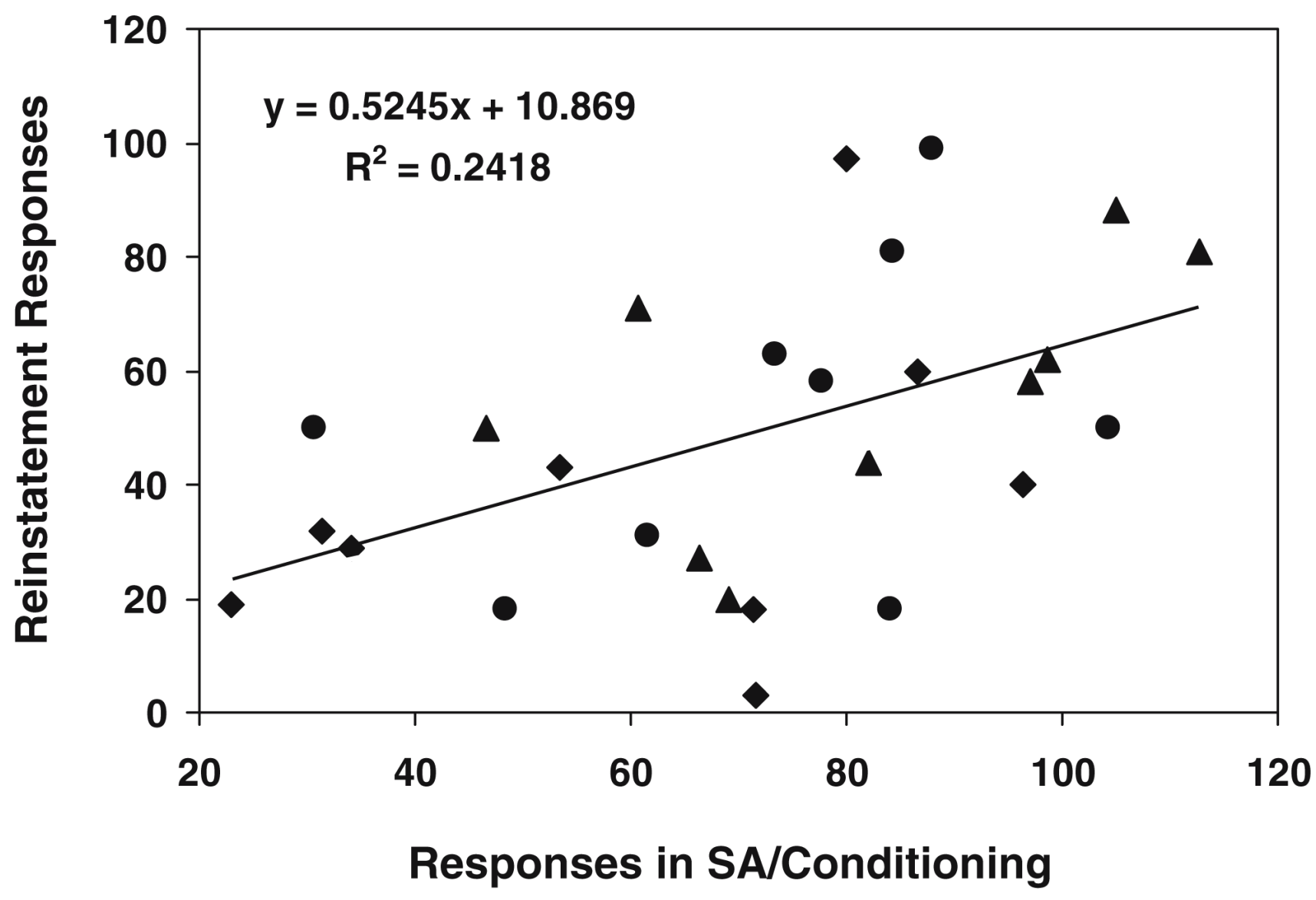

Fig. 3.

Positive correlation of the magnitude of cue-induced reinstatement with the number of responses made during self-administration/conditioning training phase (averaged across the final three sessions). Data are pooled across the three training doses of nicotine: 0.015 (filled squares), 0.03 (filled triangles), and 0.06 (filled circles) $\mathrm{mg} / \mathrm{kg} / \mathrm{infusion}$ 


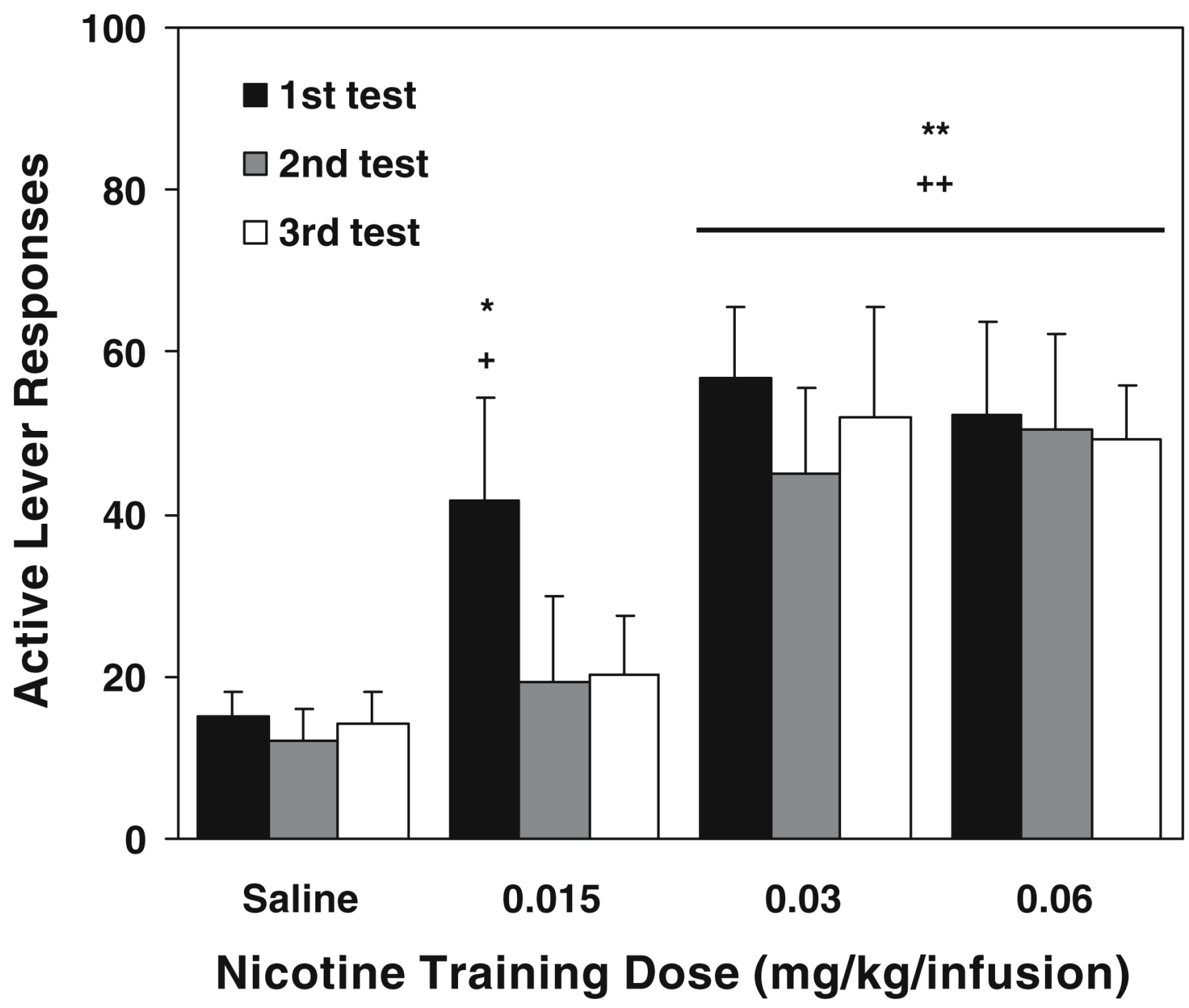

Fig. 4.

Responses on the active lever in the repeated reinstatement test sessions $(n=7-10)$. For comparison, responses in the first reinstatement test conducted the following day after 10 daily extinction sessions are shown. The second test occurred after an intervening 15 days and reextinction, i.e., 25 days after self-administration/conditioning. The third test was performed 15 days after the second test, i.e., 40 days after self-administration/conditioning. For the purpose of clarity, extinction/re-extinction responses before each reinstatement test session are not shown. The number of responses is presented as the mean \pm SEM. ${ }^{*} p<0.05$, $* * p<0.01$ different from corresponding extinction/re-extinction. $+p<0.05,++p<0.01$ different from saline group 

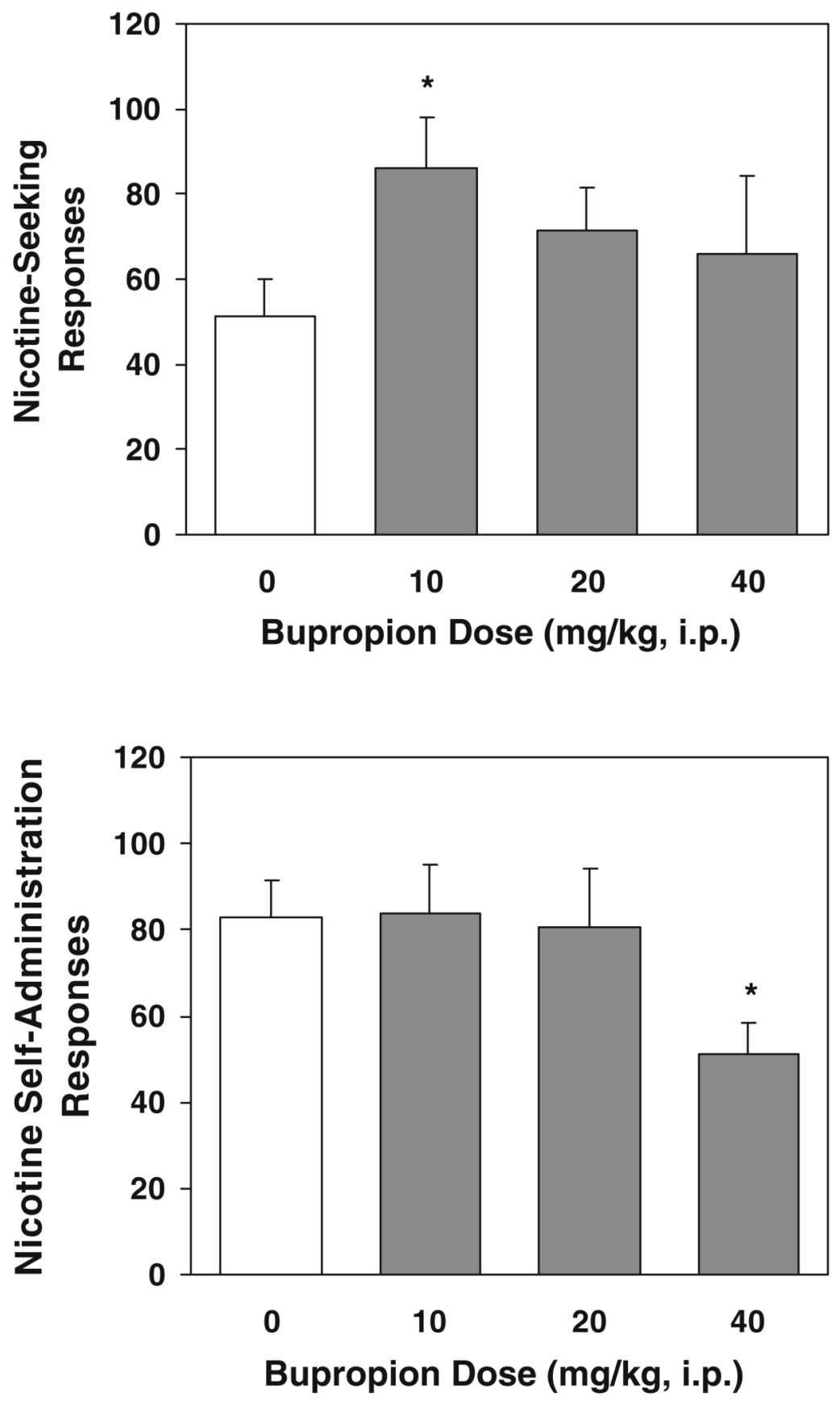

Fig. 5.

Effect of bupropion on cue-induced reinstatement of nicotine-seeking behavior (top) and nicotine self-administration (below). The reinstatement tests were conducted after completion of self-administration/conditioning training (30 daily sessions) and subsequent extinction sessions. Bupropion $(0,10,20,40 \mathrm{mg} / \mathrm{kg})$ was administered intraperitoneally to different groups of rats $(n=9-10) 30 \mathrm{~min}$ before test sessions. The self-administration/bupropion tests were performed in a separate set of rats $(n=14)$ that also received the 30 daily nicotine selfadministration training sessions before testing. Bupropion was administered by using withinsubject $(n=14)$ and Latin Square design. The number of responses is presented as the mean \pm SEM. $* p<0.05$ different from vehicle 


\section{Table 1}

Lever responses and nicotine intake averaged across the final three self-administration/conditioning sessions and body weight measured after completion of self-administration/conditioning training

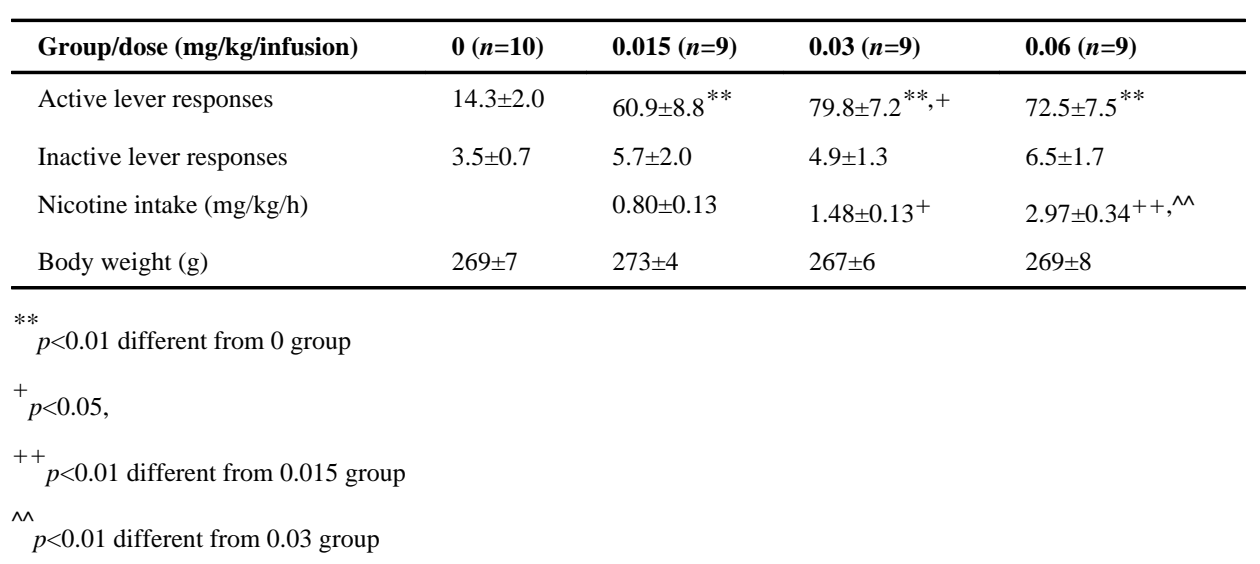

